\section{Handgrip weakness and mortality risk in COPD: a multicentre analysis}

Handgrip strength is a simple measure of upper limb muscle function that is associated with mortality in the general population and in patients with COPD. ${ }^{1}{ }^{2}$ Recently, normative values for handgrip strength have been proposed based on centile scores in $>224000$ healthy adults between 39 and 73 years of age, adjusted for age, sex, height and measurement side. ${ }^{3}$ As an illustration, in a typical 65-year-old male patient 5 th and 10 th centile of right handgrip strength range $18-28 \mathrm{~kg}$ and 20 $30 \mathrm{~kg}$, respectively, depending on the patient's height. It is unclear whether the identification of handgrip weakness based on these centiles has prognostic value in addition to known prognostic parameters like $\mathrm{FEV}_{1}$, age, dyspnoea symptoms (combined in the validated ADO index ${ }^{4}$ ) and body mass index (BMI).

Therefore, we performed an a posteriori analysis of prospectively collected multicentre data in patients with stable COPD, followed for a median of 3.9 years. $^{2}$ 5-7

Handgrip strength was assessed using a Jamar Hydraulic Hand Dynamometer (JA Preston Corporation, Jackson, Michigan, USA) in all centres. Patients were seated in a chair with the elbow in $90^{\circ}$ of flexion and touching the chest. In our analysis, both 5 th and 10th centile of the normal population were used as cut-offs to define handgrip weakness. Patients were defined as weak if one side (left or right) was below the respective cut-off.
Descriptive data are reported as mean (SD) or median (25th-75th centile). Cox proportional hazard models were used to assess the relationship between handgrip weakness and mortality. HRs and 95\% CI were calculated. Analyses were adjusted for ADO index (age, Modified Medical Research Council Dyspnea Scale (MMRC) and $\mathrm{FEV}_{1}$ ) and BMI.

In total, 998 patients (age 67 (9) years; $72 \%$ male; $\mathrm{FEV}_{1} 53$ (18) \%pred; BMI 27 (5) $\mathrm{kg} / \mathrm{m}^{2}$; MMRC 2 (1-3)) were included in the analysis. Handgrip force at baseline was 34 (11) $\mathrm{kg}$ on the right side and 31 (10) $\mathrm{kg}$ on the left side. Handgrip weakness was observed in 89 (9\%) and 152 $(15 \%)$ patients based on the 5 th and 10 th centile, respectively.

Median follow-up time was 47 months (range 24-60 months). During follow-up, 162 patients $(16 \%)$ died. The proportion of patients with handgrip weakness was $26 \%$ (10th centile) and 15\% (5th centile) in patients who died compared with $13 \%$ (5th centile) and $8 \%$ (10th centile) in survivors.

Characteristics and outcomes in different centres are provided in online supplementary table E1.

Unadjusted analysis reveals an association between handgrip weakness based on 10th centile and 5th centile cut-offs and mortality (HR 1.80 (1.25 to 2.54; $\mathrm{p}=0.002)$ and HR 1.71 (0.99 to 2.40; $\mathrm{p}=0.02)$, respectively).

After adjustment for ADO index and BMI, weakness based on 10th centile (HR $1.53(1.07$ to $2.12 ; \mathrm{p}=0.02))$ but not 5 th centile (HR 1.50 (0.96 to 2.27; p=0.08)) remained significantly related to mortality (table $1 \mathrm{~A}$ and $\mathrm{B}$, respectively). Kaplan-

Table 1 Cox proportional hazard models to define the association of handgrip weakness with mortality using 10 th centile (A) and 5th centile (B) of the healthy population as ref. 3

\begin{tabular}{|c|c|c|}
\hline & HR $(95 \% \mathrm{CI})$ & p Value \\
\hline \multicolumn{3}{|l|}{ (A) } \\
\hline \multicolumn{3}{|l|}{ Unadjusted } \\
\hline Handgrip weakness (reference: >C10) & 1.80 (1.25 to 2.54$)$ & 0.002 \\
\hline \multicolumn{3}{|l|}{ Adjusted for ADO index and BMI } \\
\hline Handgrip weakness (reference: >C10) & 1.53 (1.07 to 2.12$)$ & 0.02 \\
\hline ADO index (continuous) & 1.50 (1.36 to 1.66$)$ & $<0.0001$ \\
\hline BMI (continuous) & $0.92(0.89$ to 0.95$)$ & $<0.0001$ \\
\hline \multicolumn{3}{|l|}{ (B) } \\
\hline \multicolumn{3}{|l|}{ Unadjusted } \\
\hline Handgrip weakness (reference: >C5) & 1.71 (1.08 to 2.58$)$ & 0.024 \\
\hline \multicolumn{3}{|l|}{ Adjusted for ADO index and BMI } \\
\hline Handgrip weakness (reference: >C5) & 1.50 (0.96 to 2.27$)$ & 0.08 \\
\hline ADO index (continuous) & 1.51 (1.37 to 1.67$)$ & $<0.0001$ \\
\hline BMI (continuous) & $0.92(0.89$ to 0.96$)$ & $<0.0001$ \\
\hline
\end{tabular}

Meier survival curves of the adjusted analysis can be found in online supplementary figure E1A, B.

Based on our findings, we propose to use the 10th centile of recently published normative values as a cut-off to define handgrip weakness in patients with COPD. The identification of handgrip weakness is easy, provides prognostic information in addition to known predictors as $\mathrm{ADO}$ index and BMI and may have a role in a quick multidimensional assessment of patients with COPD.

\section{Chris Burtin, ${ }^{1}$ Gerben ter Riet, ${ }^{2}$ Milo A Puhan ${ }^{3}$ Benjamin Waschki, ${ }^{4}$ Judith Garcia-Aymerich, ${ }^{5,6}$ Victor Pinto-Plata, ${ }^{7,8}$ Bartolome Celli, $^{7}$ Henrik Watz, ${ }^{4,9}$ Martijn A Spruit ${ }^{1,10}$}

${ }^{1}$ Faculty of Medicine and Life Sciences, Rehabilitation Research Centre, Biomedical Research Institute, Hasselt University, Diepenbeek, Belgium

${ }^{2}$ Department of General Practice, Academic Medical Center, University of Amsterdam, Amsterdam, The Netherlands

${ }^{3}$ Department of Epidemiology, Biostatistics \& Prevention Institute, University of Zurich, Zurich, Switzerland ${ }^{4}$ LungenClinic Grosshansdorf, Grosshansdorf, Germany ${ }^{5}$ Centre for Research in Environmental Epidemiology (CREAL), Universitat Pompeu Fabra (UPF), Barcelona, Spain

${ }^{6}$ CIBER Epidemiología y Salud Pública (CIBERESP), Barcelona, Spain

${ }^{7}$ Pulmonary and Critical Care Medicine, Brigham and Women's Hospital, Harvard Medical School, Boston, Massachusetts, USA

${ }^{8}$ Pulmonary and Critical Care Medicine Division, Baystate Medical Center, Tufts University School of Medicine, Springfield, Massachusetts, USA

${ }^{9}$ Pulmonary Research Institute, Airway Research Center North (ARCN), German Center for Lung Research, Grosshansdorf, Germany

${ }^{10}$ Department of Research \& Education, CIRO+ Center of Expertise for Chronic Organ Failure, Horn, The Netherlands

Correspondence to Dr Chris Burtin, Rehabilitation Research Centre, Biomedical Research Institute, Faculty of Medicine and Life Sciences, Hasselt University, Diepenbeek 3590, Belgium; chris.burtin@uhasselt.be

- Additional material is published online only. To view please visit the journal online (http://dx.doi.org/10. 1136/thoraxjnl-2015-207451)

Contributors CB discussed the paper design, performed statistical analysis, wrote and submitted the paper and agrees to be accountable for all aspects of the work in ensuring that questions related to the accuracy or integrity of any part of the work are appropriately investigated and resolved. GtR discussed the paper design, assisted in data collection, critically reviewed the paper, approved the final version and agrees to be accountable for all aspects of the work in ensuring that questions related to the accuracy or integrity of any part of the work are appropriately investigated and resolved. MAP, BW, JG-A, VP-P, HW and $B C$ assisted in data collection, critically reviewed the paper, approved the final version and agrees to be accountable for all aspects of the work in ensuring that questions related to the accuracy or integrity of any part of the work are appropriately investigated and resolved. MAS came up with the topic, discussed the paper design, critically reviewed the paper, approved the final version and agrees to be accountable for all 
aspects of the work in ensuring that questions related to the accuracy or integrity of any part of the work are appropriately investigated and resolved.

Competing interests None declared.

Ethics approval Local ethics committees of different centres (CFR published papers).

Provenance and peer review Not commissioned; externally peer reviewed.

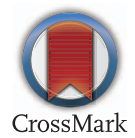

To cite Burtin C, ter Riet G, Puhan MA, et al. Thorax 2016;71:86-87.
Received 17 June 2015

Revised 10 September 2015

Accepted 6 October 2015

Published Online First 29 October 2015

Thorax 2016;71:86-87.

doi:10.1136/thoraxjnl-2015-207451

\section{REFERENCES}

1 Leong DP, Teo KK, Rangarajan S, et al. Prognostic value of grip strength: findings from the Prospective Urban Rural Epidemiology (PURE) study. Lancet 2015;386:266-73.

2 Puhan MA, Siebeling L, Zoller M, et al. Simple functional performance tests and mortality in COPD. Eur Respir J 2013;42:956-63.

3 Spruit MA, Sillen MJ, Groenen MT, et al. New normative values for handgrip strength: results from the UK Biobank. J Am Med Dir Assoc 2013;14:775.e5-11.
4 Puhan MA, Garcia-Aymerich J, Frey M, et al. Expansion of the prognostic assessment of patients with chronic obstructive pulmonary disease: the updated BODE index and the ADO index. Lancet 2009;374:704-11.

5 Watz H, Waschki B, Boehme C, et al. Extrapulmonary effects of chronic obstructive pulmonary disease on physical activity: a cross-sectional study. Am J Respir Crit Care Med 2008;177:743-51.

6 Ramon MA, Gimeno-Santos E, Ferrer J, et al. Hospital admissions and exercise capacity decline in patients with COPD. Eur Respir / 2014;43:1018-27.

7 Waschki B, Kirsten A, Holz O, et al. Physical activity is the strongest predictor of all-cause mortality in patients with COPD: a prospective cohort study. Chest 2011;140:331-42. 